\title{
WALL CONDITIONING ON TEXTOR
}

\author{
V. PHILIPPS* Institut für Plasmaphysik, Forschungszentrum Jülich GmbH \\ EURATOM Association, Trilateral Euregio Cluster, D-52425 Jülich, Germany
}

Received April 29, 2004

Accepted for Publication September 2, 2004

Proper wall conditioning has been a major element in the development of fusion energy on the way to achieve high fusion plasma performance. Various of these techniques have been pioneered in the TEXTOR tokamak and later applied successfully in various devices worldwide. The main issues are to clean the surface from surfacebounded impurities, to remove hydrogen, and to coat the entire wall surface with a thin film of a proper first-wall material. The main benefits of wall conditioning are to control the oxygen impurity content of the plasma and to offer a suitable first-wall material. Entire coating of the first wall has allowed one to control to some extent the recycling hydrogenic fluxes but in particular to study the complex coupling between the choice of wall materials and the behavior of the plasma edge. This paper presents a review of the different wall-conditioning methods used in TEXTOR and their effects on the plasma behavior. Also, new wall-conditioning concepts, compatible with steady-state magnetic fields, are outlined briefly.

KEYWORDS: wall conditioning, impurities, plasma-wall interactions

\section{INTRODUCTION}

Wall conditioning of plasma-facing surfaces has been used since the early phases of fusion research to provide the conditions for plasma production and to improve the plasma performance. ${ }^{1}$ So far, most of these regimes of improved plasma performance have relied on low plasma impurity content and some of them, in particular in diverted discharges, also on low hydrogen wall recycling. The main task in controlling the impurity influx is the control of the oxygen impurities. The original oxygen sources are air and water leaks during vacuum vessel opening. At the walls oxygen is present in the form of

\footnotetext{
*E-mail: V.Philipps@fz-juelich.de
}

adsorbed hydroxides, water, and various metal oxide compounds, while the original sources are air and water leaks, as well as water vapor absorbed during vacuum vessel openings. First-wall conditioning techniques such as glow discharge cleaning (GDC), baking, Taylor discharge cleaning, etc., aimed to remove oxygen and other loosely bound compounds from the walls. Later, deposition of thin films on the entire plasma-facing walls has been used to influence directly the material with which the plasma interacts, thereby suppressing the unwanted influx of metals from metal-based devices and to suppress the oxygen impurity content further by gettering of oxygen. In TEXTOR, early attempts have been done to form this carbidic layer on the INCONEL ${ }^{\circledR} 625$ first wall (carbidization) followed soon by deposition of an amorphous carbon film (carbonization) of the entire first wall in 1985. Carbonization, which effectively suppressed the metal influx from the wall, was replaced later by boronization that was found to be very successful in controlling the oxygen content of TEXTOR and has consequently been used later in most of the worldwide fusion devices (D-IIID, Alcator C-mod, ASDEX, ASDEX-Upgrade, JT-60, LHD, and various smaller devices). When the concept of edge radiation cooling and the radiatively improved (RI) plasma scenarios have been investigated in TEXTOR, siliconization has been explored, which offers the advantage of strong oxygen gettering but simultaneously releases a medium- $Z$ impurity to the plasma edge providing the necessary radiation for edge cooling or RI-mode performance.

Recently, new wall-conditioning techniques have been explored that can be applied under the presence of a full magnetic field as this will mostly be the case in ITER.

The work of the TEXTOR team in the field of wall conditioning has been a major contribution to the development of fusion energy, and it will be reviewed in this paper.

\section{EARLY WALL-CONDITIONING PROCEDURES}

The amount of fuel particles in present-day tokamaks and in future thermonuclear plasmas typically 
corresponds to only about a few monolayers if distributed over the surface of the entire wall. On this scale technical surfaces are not clean but contaminated with adsorbates, like water, hydrocarbons, or oxide layers. These impurities can be released during plasma operation by various processes, like sputtering by energetic particle impact but also by ion-induced desorption, electron stimulated desorption, and photodesorption, ${ }^{2}$ or simply by thermal evaporation. Hydrogen plasma impact can reduce metal oxides by forming metal-hydroxide surface complexes and finally water molecules that can be pumped out. ${ }^{3}$ Adsorbed oxygen can be released in the form of $\mathrm{CO}$ and $\mathrm{CO}_{2}$ molecules by collisional desorption in helium-conditioning plasmas. ${ }^{4}$ Typically, after the confinement time, the released impurities will return to the walls where they can be redeposited or reflected and undergo the same process again until the plasma is ramped down. All "sticking" species will be deposited on the walls while gaseous impurities might be pumped out by the vacuum pumping system. Readsorbed impurities that are not exhausted from this cycle or that are gettered in layers at locations where they are not easily removed anymore will contaminate the plasma again and determine finally the overall impurity content of the plasma.

\section{II.A. TEXTOR Under Metal Wall Conditions}

The Textor tokamak started as a full metal device, with a vacuum vessel from stainless steel, an additional tube made from INCONEL ${ }^{\circledR} 625$ representing the first wall of the plasma (liner), and stainless steel poloidal limiters. The vessel in TEXTOR can be heated to $\sim 470 \mathrm{~K}$, while the inside liner has been designed to be heated to $800 \mathrm{~K}$. Operational experience in TEXTOR extend, however, from $\sim 400$ to $700 \mathrm{~K}$. More details about the TEXTOR tokamak can be found in Refs. 5 and 6.

Conditioning under metal first-wall conditions is connected largely to the formation of metal oxides. Nickel, iron, and chromium originating from stainless steel and INCONEL ${ }^{\circledR} 625$ can form oxides that are subsequently reduced by the impact of atomic or ionized hydrogen to water vapor. Water vapor desorbs from the surfaces, is ionized, and introduces oxygen impurities to the plasma.

As suggested by Dietz ${ }^{7}$ and Waelbroeck, ${ }^{8}$ the role of water in the interaction between the plasma and wall surfaces is determined by the equilibrium of the hydrolyzation reactions of metal oxides on the wall with atomic hydrogen $(\mathrm{H})$ leaving the plasma:

$$
\begin{gathered}
\mathrm{Me}(\mathrm{O})+\mathrm{H} \\
\mathrm{Me}(\mathrm{OH})+\mathrm{Me}(\mathrm{OH}) \\
\rightarrow \mathrm{Me}+\mathrm{H}_{2} \mathrm{O} .
\end{gathered}
$$

The directions of the reactions can be deduced from the equilibrium constants for the reduction of these oxides with molecular hydrogen:

$$
\begin{aligned}
\mathrm{Me}(\mathrm{O})+\mathrm{H}_{2} & \rightarrow \mathrm{Me}+\mathrm{H}_{2} \mathrm{O} \\
\text { with } K_{p} & =p\left(\mathrm{H}_{2} \mathrm{O}\right) / p\left(\mathrm{H}_{2}\right),
\end{aligned}
$$

where $p\left(\mathrm{H}_{2} \mathrm{O}\right)$ and $p\left(\mathrm{H}_{2}\right)$ denote the partial pressures of $\mathrm{H}_{2} \mathrm{O}$ and $\mathrm{H}_{2}$ at the metal oxide surface.

Values for $K_{p}$ for various oxides as a function of temperature can be found in the literature. ${ }^{9} \mathrm{FeO}$ is more easily reduced than other oxides like $\mathrm{TiO}$ or $\mathrm{Cr}_{2} \mathrm{O}_{3}$, and $\mathrm{NiO}$, the most prominent oxide on INCONEL ${ }^{\circledR} 625$, is reduced even more easily. Hydrogen GDC has been used to reduce the metal oxides and to pump out the formed volatile reaction products by means of external vacuum pumps. Volatile products are formed because of high chemical reactivity of the atomic hydrogen. ${ }^{7}$ For effective cleaning, the formed products should not be reionized and dissociated in the plasma resulting in redeposition on the surfaces. This requires low plasma densities and low electron temperatures leading to a low ionization fraction and a large pumping speed. In the earlier TEXTOR GDC system, two anodes were moved by a bellow assembly into the main volume of the vacuum vessel system. Later, four anodes were positioned toroidally symmetrically in portholes. ${ }^{10,11}$ The wall surfaces are at ground potential, typical hydrogen pressures are in the range from $5 \times$ $10^{-4}$ to $5 \times 10^{-3}$ mbars, and the voltage between the anode and cathode is between 300 and $600 \mathrm{~V}$. A radiofrequency (rf) power $(13.6 \mathrm{MHz} ; 100 \mathrm{~W})$ is superimposed to ease the breakdown of the glow and to stabilize the plasma at low operation pressures (RG discharge). At present, four fixed antennas are used that are mounted flashlike in the TEXTOR first wall (liner) $90 \mathrm{deg}$ toroidally distinct. The total feedback stabilized current is at $6 \mathrm{~A}$, corresponding to a current density of $\sim 10 \mu \mathrm{A} / \mathrm{cm}^{2}$. For short-term conditioning such as after major disruptions, short-lasting vacuum leaks, or uncontrolled outgassing from new installed components, short-term (15 to $20 \mathrm{~min}$ ) He GDC is used, while for conditioning after openings and water leaks or to control the isotopic hydrogenic wall inventory, GDC in $\mathrm{H}$ or D over several hours (typically 2 to $8 \mathrm{~h}$ ) is used. A model for the temperature-dependent cleaning effectiveness of a glow discharge as a function of the glow current density and hydrogen pressure has been developed ${ }^{10,12}$ that describes well the behavior in TEXTOR. The total removal of volatile impurities from TEXTOR after the initiation of a glow discharge in hydrogen corresponds typically to a surface coverage of 100 and 200 monolayers, respectively. ${ }^{13}$ Figure 1 shows the increase of the main partial pressures during hydrogen RG discharge after a long opening period. The main molecules pumped out, in the order of their magnitude, are $\mathrm{H}_{2} \mathrm{O}, \mathrm{CO}, \mathrm{CH}_{4}, \mathrm{C}_{2} \mathrm{H}_{x}$, and $\mathrm{CO}_{2}$.

Electron cyclotron resonance (ECR) cleaning discharges ${ }^{14}$ with $2.45-\mathrm{GHz}$ sources and a variable toroidal field moving the resonance zone along the major radius within the vessel were used in TEXTOR. Hydrogen-ECR and glow cleaning have been compared showing about the same cleaning effectiveness at similar power input levels. This shows the importance of atomic hydrogen for the cleaning effect since the dominant wall fluxes in these ECR plasmas are neutral hydrogen atoms. 


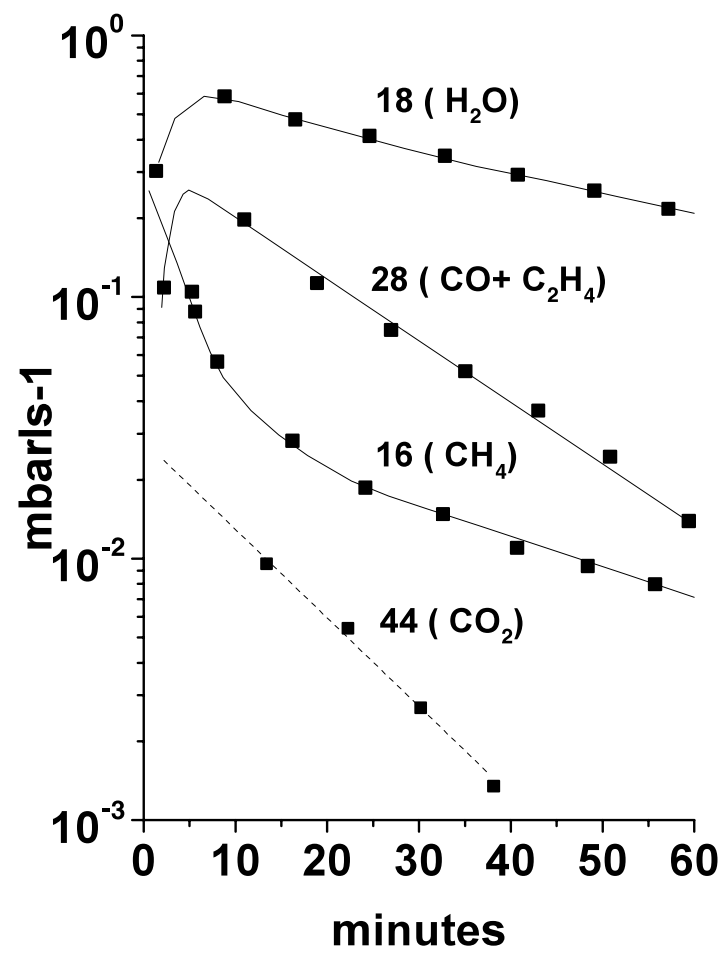

Fig. 1. Release rate of different masses by GDC in hydrogen after a long opening of TEXTOR. The wall temperature was $150^{\circ} \mathrm{C}$.

\section{CONDITIONING WITH WALL COATINGS}

\section{III.A. Carbonization}

The development of carbonization started in early 1980 in TEXTOR, when $\mathrm{CH}_{4}$ seeded $\mathrm{RG}$ discharges were used in laboratory experiments to study the surface conditioning of oxidized stainless steel surfaces. ${ }^{10,15}$ Similar exploratory experiments were later made in TEXTOR (Ref. 16). The deposited carbon was identified to be in a "carbidic" chemical binding state in a broader diffusion profile inside the wall material forming preferentially carbidic $\mathrm{CrC}$ bonds in INCONEL ${ }^{\circledR} 625$ (Refs. 17 and 18). This method was therefore called carbidization. Since 1984 carbonization was studied systematically for in situ carbon deposition, leading to larger carbon deposition fluxes of $10^{13}$ to $10^{14} \mathrm{~cm}^{-2} \cdot \mathrm{s}^{-1}$ and fluencies $\left(10^{17} \mathrm{~cm}^{-2}\right)$ to the wall, resulting in the deposition of amorphous carbon layers $(\mathrm{a}-\mathrm{C}: \mathrm{H})$ on the entire wall surface within deposition times of typically 3 to $5 \mathrm{~h}$ (Ref. 19). Carbonization was done using $\mathrm{rf}$ power $(\sim 250 \mathrm{~W})$ and a positive direct-current bias $(\sim 600$ to $1000 \mathrm{~V})$ with the same two antennas as used routinely for GDC cleaning. The liner and the limiters were at ground potential in a continuous flow of $\mathrm{D}_{2}$ and $\mathrm{CD}_{4}$ with a typical $\mathrm{CD}_{4} / \mathrm{D}_{2}$ ratio of 0.2 to 0.3 . The total pressure in the vessel was usually between 1 to $3 \times 10^{-5} \mathrm{~Pa}$.

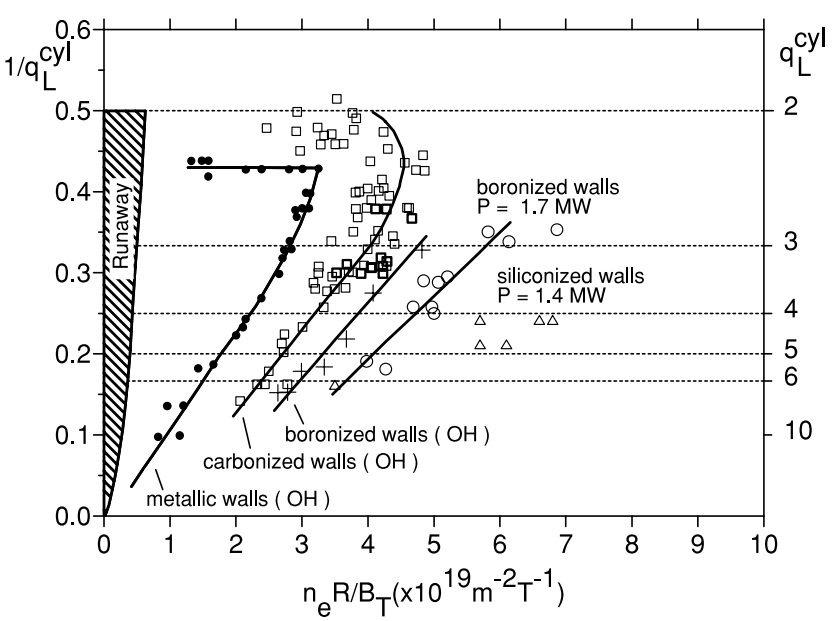

Fig. 2. Operational regime of TEXTOR with ohmic heating for various wall-coating situations. The data for carbonized conditions include both discharges with carbonized wall and carbonized steel limiter and carbonized wall and graphite limiters.

The carbonization produces amorphous hydrogenrich "diamondlike" carbon film ${ }^{20}$ with a $\mathrm{H} / \mathrm{C}$ ratio of $\sim 0.4$ for deposition at $T<150^{\circ} \mathrm{C}$. The films are transparent and hard and have a homogeneous structure. After carbonization an almost complete suppression of metal impurities in the plasma and a significant reduction of the oxygen impurity radiation are generally observed. Also, the hydrogen recycling properties are influenced, leading to an improvement in plasma performance as seen in low values of $Z_{\text {eff }}$ and low radiation fractions. Figure 2 shows the operational regime of TEXTOR before and after carbonization by means of a Hugill diagram.

Plasma heating by electromagnetic waves was largely improved, ${ }^{21}$ and the accessible density regime had been increased by a factor of $\sim 1.5$. An initial reduction of oxygen by a factor of $\sim 5$ compared to metallic surfaces has been observed. However, this reduction is transient over only about 20 discharges and saturates at a factor of $\sim 2$ to 3 net reduction. Carbonization has later been used in many other devices like ASDEX, JET, JIPP, T II-U, DIII-D, Heliotron-E, and others.

During the carbonization phase of TEXTOR, the carbon films had been removed prior to a new wall coating in a GDC $\mathrm{H}$ plasma with a removal rate of typically 0.1 monolayer/min. This has to be compared with a typical deposition rate of about 1 monolayer/min.

\section{III.B. Boronization}

After carbonization, the remaining plasma contaminants were mainly carbon and oxygen. It was believed that water vapor desorbing from oxidized metal surfaces that are not carbonized (e.g., the portholes or backside of 
the liner) are the primary oxygen sources. The desorbing water is ionized, and the oxygen is implanted into the near-surface region of the carbon layers. It can be easily desorbed by particle bombardment in the form of $\mathrm{CO}$ during the discharges and further recycling in the device. ${ }^{8,22}$ Glow discharges can deplete the near-surface layer from this oxygen on the plasma exposed areas that can be reached by the GDC process by the release of $\mathrm{CO}$ and $\mathrm{H}_{2} \mathrm{O}$. In tokamak discharges, this effect is only transient, and the oxygen flux recovers continuously most probably fed by oxygen released from those hiddden areas. The oxygen fluxes in TEXTOR increase in the scrape-off layer (SOL) when approaching the wall, showing that the primary source of the oxygen is the entire first wall, and screening occurs in the SOL (Ref. 23). A further reduction of the residual oxygen level in the plasma was the main emphasis of boronization in TEXTOR (Ref. 24).

Boronization was done first in 1988 in a $\mathrm{He}_{-} \mathrm{CH}_{4}-$ $\mathrm{B}_{2} \mathrm{H}_{6}$ mixture (80:10:10) in the same RG-GDC discharge as used for the standard TEXTOR carbonization. This approach was chosen in order to change smoothly from the known behavior of the carbon layers to the new boroncontaining layers. Major modifications were necessary for the gas injection and the pump system to ensure the safe handling of the toxic and explosive $\mathrm{B}_{2} \mathrm{H}_{6}$ gas. The safety assessment and the arrangement used at TEXTOR are described in Ref. 25. Initially, the addition of $\mathrm{CH}_{4}$ was done aiming for a bulk composition of $\mathrm{B} / \mathrm{C}=1$ in the deposited film. Helium was used as a carrier gas to provide films with low hydrogen concentration. Later, pure boron films were deposited in a $\mathrm{He} / \mathrm{B}_{2} \mathrm{H}_{6}$ mixture.

The boronization produces amorphous boroncontaining carbon films a-C/B:H (Ref. 26). The advantage of these films is their strong ability to getter oxygen and their lower chemical erosion by thermal and energetic hydrogen species. ${ }^{27}$ In contrast to carbon films on which oxygen recycles after a short transient phase to $\mathrm{CO}$ and $\mathrm{CO}_{2}$, oxygen is gettered in the boron films. X-ray photoelectron spectroscopy has revealed the formation of $\mathrm{B}_{2} \mathrm{O}_{3}$ (Ref. 28), which is a solid with low vapor pressure.

The most striking observation after first boronization in TEXTOR was the strongly reduced plasma radiation level in comparison to similar discharges under carbonized conditions. Carbon radiation decreased by a factor of $\sim 2$, but the most pronounced reduction was seen in the oxygen line radiation in the plasma, the oxygen fluxes from the limiters, and the neutral $\mathrm{CO}$ and $\mathrm{CO}_{2}$ pressure near the walls, which decreased by factors between 3 and 6 (Ref. 29). Boronization also affected the recycling behavior of TEXTOR. While the recycling under carbonized walls at $T=150^{\circ} \mathrm{C}$ could easily reach values larger than unity leading to a loss of plasma density control, these problems disappeared after boronization. The recycling was less than one during current flattop, and the shot-to-shot reproducibility was excellent, making active feedback control of the electron density easy. In addition, density excursions caused by ion cyclotron res-

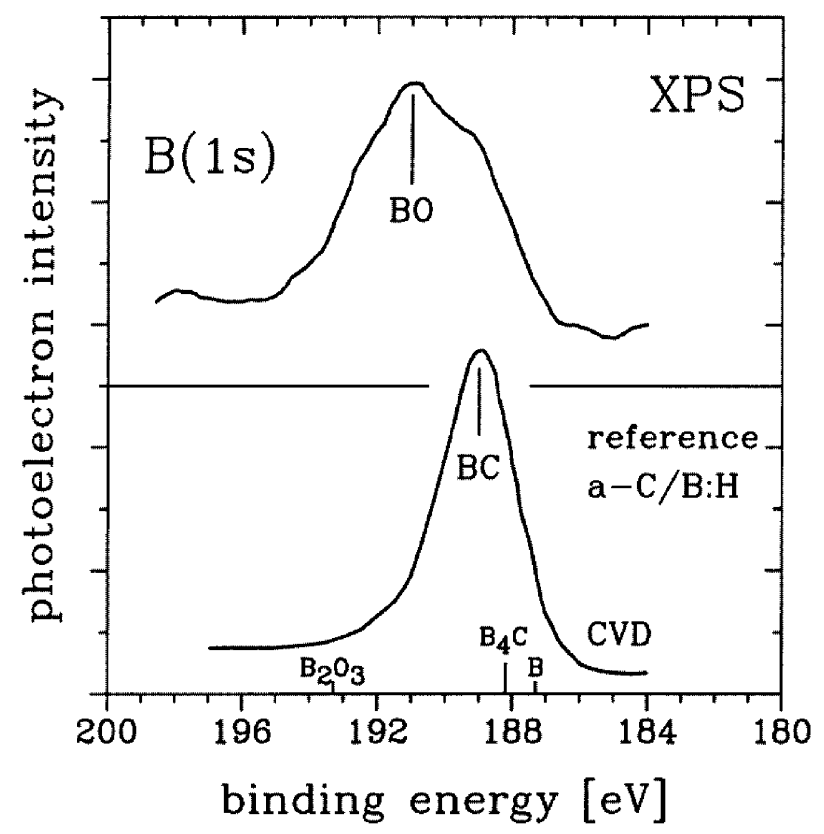

Fig. 3. Energy spectrum of the B (1-s) photoelectrons for redeposited layers from the boronized TEXTOR (top) and a boronization film with $\mathrm{B} / \mathrm{C}=1$ for reference. Most B atoms of the redeposited film are bound to oxygen, which has been gettered from the SOL plasma, whereas no oxygen contamination is observed in the reference film (from Ref. 46).

onance (ICR) heating (ICRH) pulses could be avoided ${ }^{30}$ such that high-power ICRH pulses could be made under full-density feedback conditions.

The improved density control is due to the lower hydrogen content of the boron films at this wall temperature. The reduction of oxygen impurities is due to the fact that oxygen is retained in redeposited layers as a nonvolatile oxide where most of the B atoms are bonded with $\mathrm{O}$ atoms, as shown in Fig. 3.

A reciprocal relation between the oxygen plasma impurity concentration and the amount of oxygen gettered in the redeposited film has been found in TEXTOR by collector probe measurements at various times following boronization. ${ }^{31}$ Similar observations have been made for redeposited layers after beryllium gettering in JET (Ref. 32).

\section{III.C. Siliconization}

In late 1992 the method of siliconization was developed in TEXTOR. The results on performance, plasma edge behavior, and impurity release behavior have been published in Refs. 33, 34, and 35. A pure amorphous hydrogen (deuterium)-rich silicon film $(\mathrm{a}-\mathrm{Si}: \mathrm{H}, \mathrm{D})$ is deposited by an rf GDC (similar to carbonization and boronization) but in a throughflow of $0.2 \mathrm{SiD}_{4}+0.8 \mathrm{He}$. 
Typical coating thickness was $\sim 100 \mathrm{~nm}$ with good adherence to the metallic liner and the graphite limiters and with an amorphous structure. The $\mathrm{H} / \mathrm{Si}$ ratio is typically $\sim 0.2$ but can increase after tokamak discharges because of the codeposition of carbon, which increases the storage capacity for hydrogen. ${ }^{36}$ This results in strong wall pumping lasting for many discharges. ${ }^{37}$ With siliconized walls the lowest oxygen concentrations ever measured in TEXTOR have been obtained - a factor of $\sim 2$ lower compared with boronization, except at low plasma densities. In general, the plasma behaved qualitatively different compared with the low-Z boron coating. This is mainly due to the physical sputtering nature of $\mathrm{Si}$ release that shows, because of the higher mass, a more pronounced decrease with decreasing plasma temperature and rising density.

At lower plasma density the radiation level from $\mathrm{Si}$ radiation due to intrinsic Si sputtering is high but decreases with density and reaches similar low levels at high plasma densities as observed after boronization (Fig. 4). It is particularly noteworthy that the maximum attainable density in the siliconized TEXTOR is significantly higher $(\sim 30 \%)$ than that after boronization although the atomic number of $\mathrm{Si}$ and its radiation potential are higher than that of $\mathrm{B}$ and $\mathrm{C}$. This is due to the fact that the dominant impurity species at high densities remains physically sputtered Si while under boronized wall conditions oxygen and carbon radiation dominate. The oxygen and carbon production yields do not decrease with increasing density in a similar manner as observed for $\mathrm{Si}$. This changes the balance between increasing impurity radiation and decreasing impurity influx that increase both with increasing plasma density This leads also to a

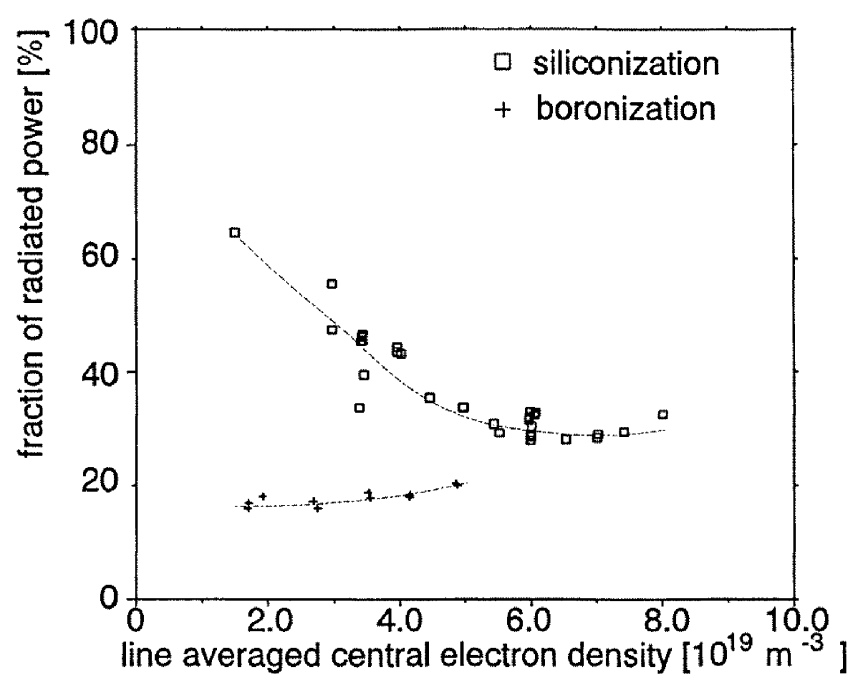

Fig. 4. Density dependence of the total radiation for boronized and siliconized wall conditions in TEXTOR. Data are for hydrogen discharges with 1.5 MW external heating (from Ref. 34). different onset of MARFE formation with density, which finally determines the radiation density limit in TEXTOR. Thus, one benefit of Si-coated walls is that higher densities can be obtained. Also, because of the strong Si radiation, the energy transport at the plasma boundary and the plasma edge temperature can be reduced by increasing the edge radiation leading to radiatively cooled discharges, similar to the case with neon injection, which is regularly done in TEXTOR (see Ref. 38). Improved RI-modes have been obtained with Si radiation fully provided by intrinsic Si sputtering. ${ }^{33}$

\section{OTHER CONDITIONING METHODS EXPLORED IN TEXTOR}

Flashing of TEXTOR before plasma operation with (molecular) diborane gas has been done. This has reduced the oxygen plasma contamination in subsequent discharges. ${ }^{40}$ The effect is assumed to be caused by a reaction of $\mathrm{B}_{2} \mathrm{H}_{6}$ with metal oxides resulting in the formation of stable boron oxide and metal carbides finally reducing the release of water. A reduced outgassing of $\mathrm{H}_{2} \mathrm{O}$ is also measured after this procedure.

Trimethylboron ${ }^{41}$ and di-silane ${ }^{42}$ have been injected into the SOL during tokamak discharges. Boron and silicon are redeposited on the walls while the hydrogenic atoms fuel the plasma with the same efficiency as deuterium gas, whereas the impurities are well shielded by the SOL from penetrating into hot plasma zones. In case of complete fueling of the plasma with trimethylboron, the radiated power fraction and $Z_{\text {eff }}$ are essentially unchanged compared to $\mathrm{D}_{2}$-fueled discharges, and the performance of the tokamak plasma is not adversely affected. Fully $\mathrm{SiD}_{6}$-fueled plasmas show a higher radiation fraction compared with the D-fueled plasmas, in particular, at higher plasma densities. ${ }^{33}$

\section{WALL CONDITIONING IN FUTURE DEVICES}

The requirements on wall conditioning in ITER and other future large devices are not very clear because of the long pulse lengths that will condition the plasmafacing surfaces more effectively than in present devices with low duty cycles. However, plasma start-up and rampdown phases are critical in particular after events like disruptions, venting, water, or air leaks. Moreover, the long pulse lengths of devices require superconducting magnets stay switched on for long times to avoid cycling the coils. Thus, routine wall-conditioning techniques must be developed with magnetic fields that exclude standard glow discharge. Also, pulse discharge cleaning and Taylor discharge cleaning are not adequate because of the fatigue of the components. GDC is foreseen as a standard 
option for the operation phases without magnetic field on.

Thus, ECR- and ICR-based conditioning plasmas have been explored in TEXTOR both for hydrogen removal from plasma-facing surfaces and for thin film deposition. ${ }^{39}$ Pulsed ICRH plasmas at full magnetic field have been found to be effective to remove hydrogen from the walls with a rate larger than in standard GDC plasmas. ${ }^{43}$ Similar experiments have been done in Tore Supra ${ }^{44}$ and HT7. Not enough is know at present about the spatial distribution, the spectrum, and the energy distribution of the species impinging on the first wall with this technique. ICRH-generated plasmas have also been used to deposit boron-conditioning films in TEXTOR ${ }^{45}$ This has been done in pulsed ICRH-generated plasmas at $2.5 \mathrm{~T}$ achieved with a rate comparable to normal GDC. However, in TEXTOR the film thickness was toroidally and poloidally inhomogeneous. In the meantime ICRHgenerated wall coating is routinely used in HT7 for boronization, ${ }^{46}$ and the authors claim a much better homogeneity compared to the results obtained in TEXTOR.

\section{REFERENCES}

1. J. WINTER, "A Comparison of Tokamak Operation with Metallic Getters (Ti, Cr, Be) and Boronization," J. Nucl. Mater., 176-177, 14 (1990).

2. V. PHILIPPS, E. VIETZKE, M. ERDWEG, and J. WINTER, "Photon Induced Impurity Production in TEXTOR," J. Nucl. Mater., 200, 355 (1993).

3. J. WINTER et al., "Boronization in Textor," J. Nucl. Mater., 162164, 713 (1989).

4. G. L. JACKSON, T. S. TAYLOR, and P. L. TAYLOR, "Particle Control in DIII-D with Helium Glow Discharge Conditioning," J. Nucl. Fusion, 30, 2305 (1990).

5. U. SAMM, "TEXTOR: A Pioneering Device for New Concepts in Plasma-Wall Interaction, Exhaust, and Confinement," Fusion Sci. Technol., 47, 73 (2005).

6. O. NEUBAUER et al., "Design Features of the Tokamak TEXTOR," Fusion Sci. Technol., 47, 76 (2005).

7. K. J. DIETZ, F. WALBROECK, and P. WIENHOLD, "Origin of Impurities in Hydrogen Plasmas," Jül-1448, Forschungszentrum Jülich (1977).

8. F. WAELBROECK, T. BANNO, H. G. ESSER, L. KÖNEN, V. PHILIPPS, P. WIENHOLD, and J. WINTER, "The Use of the RG Conditioning System to Examine Some Recycling Mechanisms Occurring in an All-Carbon Surrounding," J. Nucl. Mater., 162-164, 496 (1989).

9. G. W. C. KAYE and T. H. LABY, Tables of Physical and Chemical Constants, Longman, New York (1973).

10. F. WAELBROECK, J. WINTER, and P. WIENHOLD, "Cleaning and Conditioning of the Walls of Plasma Devices by Glow Discharges in Hydrogen," J. Vac. Sci. Technol., 2, 1521 (1984).

11. J. WINTER, "Wall Conditioning of Fusion Devices by Reactive Plasmas," J. Nucl. Mater., 161, 265 (1989).

12. F. G. WAELBROECK et al., Proc. IX Int. Vac. Congress-V. Int. Conf. Solid Surfaces, Madrid, 1983, p. 693 (1983).
13. J. WINTER, F. WAELBROECK, P. WIENHOLD, H. G. ESSER, L. KÖNEN, M. BRAUN, B. EMMOTH, and H. E. SÄTHERBLOM, "Wall Conditioning of TEXTOR," J .Nucl. Mater., 128-129, 841 (1984).

14. Y. SAKAMOTO, Proc. 9th Int. Vacuum Congress and 5th Int. Conf. Solid Surfaces, Madrid, Spain, September 26-October 1, 1983, p. 716 (1983).

15. F. WAELBROECK, J. WINTER, I. ALI-KHAN, P. WIENHOLD, B. BRANDT, and K. J. DIETZ, "Cleaning and Conditioning of the Walls of Plasma Devices by Glow Discharges in Hydrogen," JÜL1692, Forschungszentrum Jülich (1980).

16. R. E. CLAUSING, K. G. TSCHERSICH, H. P. FLEISCHHAUER, L. HEATHERLY, F. WAELBROECK, J. WINTER, P. WIENHOLD, Y. SAKAMOTO, S. ISHII, and K. YANO, "Surface Composition Changes of Inconel 625 During RG and ECR Discharge Cleaning of TEXTOR at $300^{\circ}$ C," J. Nucl. Mater., 122-123, 1145 (1984).

17. K. BESOCKE, G. FLENTJE, J. WINTER, P. WIENHOLD, and H. G. ESSER, "Investigation of Liner Samples Exposed to an In-Situ Carbidization in TEXTOR," J. Nucl. Mater., 136, 124 (1985).

18. J. WINTER et al., "Surface Conditioning of Liners and Limiters of Textor by Plasmachemical Carbon Deposition," J. Nucl. Mater., 122-123, 1187 (1984).

19. J. WINTER, "Carbonization in Tokamaks," J. Nucl. Mater., 145147, 131 (1987).

20. J. C. ANGUS, P. KOIDL, and S. DOMITZ, in Plasma Deposition of Thin Films, CRC Press, Boca Raton, Florida (1985).

21. G. H. WOLF et al., "Properties, Control and ICR-Heating of the Plasma in TEXTOR," Plasma Phys. Control. Fusion, 28, 1413 (1986).

22. F. WAELBROECK et al., "Origin of Low Z Impurities in TEXTOR with an "All Carbon" Surrounding," J. Nucl. Mater., 145147, 665 (1987).

23. U. SAMM et al., "Plasma Edge Physics in the Textor Tokamak with Poloidal and Toroidal Limiters," J. Nucl. Mater., 162-164, 24 (1989).

24. J. WINTER et al., "Boronization in TEXTOR," J. Nucl. Mater., 162-164, 713 (1989).

25. H. G. ESSER, H. REIMER, J. WINTER, and D. RINGER, "First Boronization of TEXTOR-Concept and Realization," Fusion Technol., 1, 791 (1988).

26. J. VON SEGGERN et al., "Properties of a-C/B : H Films Relevant to Plasma-Surface Interactions," J. Nucl. Mater., 176-177, 357 (1990).

27. E. VIETZKE, V. PHILIPPS, K. FLASKAMP, J. WINTER, and S. VEPRÉK, "Radiation Enhanced Sublimation of Boron Containing Carbon Materials," J. Nucl. Mater., 176-177, 481 (1990).

28. R. ZEHRINGER, H. KÜNZLI, P. OELHAFEN, and C. HOLLENSTEIN, "Oxidation Behaviour of Boron Carbide," J. Nucl. Mater., 176-177, 370 (1990).

29. F. WAELBROECK et al., "Influence of Boronization on the Plasma Performance in TEXTOR," Plasma Phys. Controlled Fusion, 31, 2, 185 (1989)

30. J. M. BEUKEN et al., Proc. 15th European Conf. Controlled Fusion and Plasma Heating, Dubrovnik, Croatia, May 1988, P8 El 34 (1988).

31. P. WIENHOLD, M. RUBEL, J. VON SEGGERN, H. KÜNZLI, I. GUDOWSKA, and H. G. ESSER, "Collection of Oxygen in the Scrape-Off Layer Depending on Boron Conditioning of TEXTOR," J. Nucl. Mater., 196-198, 647 (1992). 
32. J. P. COAD et al., "Evolution of Be-Containing Layers in the JET Boundary Region," J. Nucl. Mater., 176-177, 145 (1990).

33. J. WINTER et al., "Improved Plasma Performance in TEXTOR with Silicon Coated Surfaces," Phys. Rev. Lett., 71, 10, 1550 (1993).

34. U. SAMM et al., "Plasma Edge Physics with Siliconization in TEXTOR,” J. Nucl. Mater., 220-222, 25 (1995).

35. V. PHILIPPS et al. "Impurity Release and Recycling Behaviour in TEXTOR-94 with Siliconised Walls," J. Nucl. Mater., 290-293, 1190 (2001).

36. J. VON SEGGERN et al., "Properties of Thin a-C:H Coatings Applied to TEXTOR,” J. Nucl, Mater, 220-222, 677 (1995).

37. T. BANNO et al., "Particle Balance Studies in TEXTOR during Experiments of Pellet Injection, Helium Injection and ICR Heating," J. Nucl. Mater., 220-229, 478 (1995).

38. B. UNTERBERG et al., "The Radiative Improved Mode at TEXTOR: Power Exhaust and Improved Confinement at High Density," Fusion Sci. Technol., 47, 187 (2005).

39. H. G. ESSER et al., "ICRF Wall Conditioning at TEXTOR-94 in the Presence of a 2.25 Magnetic Field," J. Nucl. Mater., 241-243, 861 (1997).
40. J. WINTER, "A Comparison of Tokamak Operation with Metallic Getters (Ti, Cr, Be) and Boronization," J. Nucl. Mater., 176-177, 14 (1990).

41. H. G. ESSER, V. PHILIPPS, H. B. REIMER, and P. WIENHOLD, "Plasma Discharge Fuelling by Trimethylboron-A New Wall Conditioning Technique," J. Nucl. Fusion, 32, 278 (1992).

42. U. SAMM et al., "Plasma Edge Physics with Siliconization in TEXTOR,” J. Nucl. Mater., 220-222, 25 (1995).

43. E. GAUTHIER et al., Proc. 28th European Conf. Controlled Fusion and Plasma Physics, Madeira, Portugal, June 18-22, 2001, Europhysics Conference Abstracts, Vol. 25A, P-5.094.

44. E. GAUTHIER and E. DE LA CAL, J. Nucl. Mater., 241-243, 553 (1997)

45. H. G. ESSER et al., "Deposition of a-C/B:D Layers by ICRF Wall Conditioning in TEXTOR-94," J. Nucl. Mater., 266-269, 240 (1999).

46. B. XIAO, J. LI, and HT-7 TEAM, "Hydrogen Removal via ICRF Technique on HT-7-Experiment and Modelling on Neutral Energies," J. Nucl. Mater., 313-316, 163 (2003). 